\title{
HOW BAD IS THE FAKE NEWS PROBLEM?
}

\section{The role of baseline information in public perceptions}

\section{Benjamin A. Lyons, Vittorio Merola, and Jason Reifler}

In February 2019, the UK Parliament released a scathing report likening Facebook executives to "digital gangsters" for how they treat user data. The damning report grew out of a larger effort to understand the role of social media in elections specifically and in undermining democratic institutions more generally. Of particular concern was how social media platforms help spread "fake news" and other forms of disinformation. It is understandable why the UK Parliament might express an interest in how digital media could negatively affect democracy. After all, the British firm Cambridge Analytica was caught up in scandals for the role it may have played in two elections with surprising outcomes - the UK Brexit referendum and Donald Trump's shocking victory in the 2016 US presidential election.

As these campaigns were unfolding - especially the US presidential election the novel form of political content "fake news" was beginning to be noticed. Fake news produced content that was false and showed no regard to accuracy or journalistic standards. These sites would often pass themselves as real news sites. Some of the more infamous claimed that Pope Francis endorsed Donald Trump for president (he did not), that an FBI agent involved in the release of Clinton emails was involved in a murder-suicide (no such event happened), and that those protesting the outcome of the election were being paid by George Soros (also not true). Some of these articles were shared on Facebook hundreds of thousands - if not millions - of times. The combination of a novel form of media with some outrageously large engagement metrics occurring at the same time as unexpected election results leads to a natural, if naive, inference - lots of people consumed fake news, and this consumption has had an effect on these election outcomes.

However, anecdotal news coverage is now being replaced by coverage of empirical research into fake news (Grinberg, Joseph, Friedland, Swire-Thompson, \& 
Lazer, 2019; Guess, Nyhan, \& Reifler, 2018; Guess, Nagler, \& Tucker, 2019). Contrary to the despair of popular narratives, fake news accounted for limited amounts of news consumption during the 2016 election. Specifically, this research finds that about one in four (27\%) American adults visited a fake news website in the lead-up to the 2016 election, visiting an average of 5.5 articles each, and "fake news websites represented an average of approximately $2.6 \%$ of all the articles Americans read on sites focusing on hard news topics" during this time (Guess et al., 2018). Exposure to fake news has further declined between 2016 and 2018 (Guess et al., 2019).

News headlines may simplify these findings, giving readers a contextualized summation such as "Fake News': Wide Reach but Little Impact, Study Suggests" (Carey, 2018) or "Majority of Americans Were Not Exposed to 'Fake News' in 2016 U.S. Election, Twitter Study Suggests” (Fox, 2019). Readers are heavily influenced by the headline of a news article (e.g., Ecker, Lewandowsky, Chang, \& Pillai, 2014). However, it is less clear how the statistical baselines established in the research themselves might influence public views about fake news (e.g., Kessler, Levine, Opitz, \& Reynolds, 1987) - in the absence of a summative headline, how does the public make sense of information about how much of the public was exposed to fake news, and how much they read, on average?

\section{Theory}

\section{Potential effects of statistical baselines}

Research shows fake news consumption during the 2016 election was less than the popular imagination held, and limited to a small segment of the population (Grinberg et al., 2019; Guess et al., 2018; Guess, Lyons, Montgomery, Nyhan, \& Reifler, 2019). However, this academic research is unlikely to captivate the public as fully as the original introduction to the problem of fake news. The public is likely unaware of the actual prevalence of fake news consumption, instead making inferential errors (e.g., Ahler \& Sood, 2018) based on salient cases. As such, public opinion surveys show generally high rates of concern. Pew Research Center (Barthel, Mitchell, \& Holcomb, 2016), for example, found that 64\% of Americans thought fake news was sowing "a great deal of confusion" following the election, and 71\% said they often or sometimes saw "completely made-up" political news online.

Providing baseline statistical information about consumption may influence subjective judgments about fake news consumption's prevalence, its prevalence over time, its prevalence among select demographic subgroups, and overall concern about the problem and support for solutions. However, it is unclear which direction such statistical baselines, on their own, may influence these perceptions and attitudes. It is possible the information may contrast with an assumed widespread prevalence and drive down subjective sense of prevalence and concern. On the other hand, the public may struggle to place the baselines in an appropriate context, and the presentation of the information about consumption, 
regardless of its size, may act as a cue raising the salience of the fake news problem, leading to greater subjective assessments of prevalence and concern. The effects of statistical information may also depend on individual characteristics, such as familiarity (e.g., Facebook use) and interest in and knowledge about politics, as well as cognitive traits such as cognitive reflection, need for evidence, and reliance on intuition.

\section{Decreasing perceived prevalence and concern}

One way statistical baselines about fake news consumption may reduce perceived consumption and concern is by providing a descriptive norm (e.g., Rimal \& Real, 2005). Based on public opinion data (Barthel et al., 2016), the public's existing perceptions of fake news consumption may be seen as a normative misperception (Neighbors, Dillard, Lewis, Bergstrom, \& Neil, 2006). As such, providing actual baseline information may bring perceptions in line with reality. The statistical baselines of actual 2016 election consumption - 27\% of all Americans exposed to at least one fake news article, an average of 5.5 articles each - may contrast with more extreme existing inferences derived from anecdotal experience, and serve to drive down subjective assessments of public consumption (e.g., "very little"? "A lot"?) and concern about the issue going forward.

\section{Increasing perceived prevalence and concern}

On the other hand, people are notoriously bad at making sense of statistical information (Hoffrage, Lindsey, Hertwig, \& Gigerenzer, 2000). Providing statistical baselines, then, may actually increase subjective assessments of fake news' reach and personal concern. Importantly, "[i]t is the personal meaning of information not the objective details which is stored and made available for recall in decision making" (Kessler et al., 1987, p. 367; Neisser, 1978). Any baseline may only serve to concretize a previously vague problem.

The availability heuristic (e.g., An, 2008; Tversky \& Kahneman, 1974) may account for such an outcome. The ease with which individuals bring exemplars for events to mind influences downstream perceptions and judgments about the probability or prevalence of such events (Folkes, 1988; MacLeod \& Campbell, 1992). Providing baseline statistics could serve as a sort of exemplar, making the problem of fake news consumption more available at the top of the reader's mind, resulting in greater subjective assessments of prevalence and concern. In other words, by raising the salience of fake news, baseline consumption information could increase the intensity of subjective assessments (Carroll, 1978).

\section{Effects on group-centric biases}

In addition to generalized overestimation of fake news consumption (Barthel et al., 2016), individuals likely exhibit group-centric biases in beliefs about who 
consumes fake news (e.g., Ahler \& Sood, 2018; Turner, Brown, \& Tajfel, 1979). Voters who supported Hillary Clinton likely estimate that Trump voters consumed fake news at greater rates than other Clinton voters did, and vice versa. Voters over 60 may assume that younger voters consumed greater amounts of fake news than did their age group, and vice versa. College graduates may assume that those without a college degree were more susceptible to fake news, though it is not clear whether this would be a symmetric perceptual relationship due to widespread assumptions about the positive effects of higher education. Providing baseline information about overall fake news consumption may work to widen these gaps when participants are asked to assess whether various demographic groups consumed less than average, more than average, or about average amounts of fake news. If a statistical baseline treatment works to raise the salience of fake news and inflate subjective assessment of its prevalence, individuals may then project favorable biases onto the distribution of their heightened assessments of general consumption. If fake news looms as a larger problem in the reader's mind, they may then account for this higher rate of perceived consumption by attributing it (disproportionately) to an outgroup, rather than to the social categories to which they belong (Turner et al., 1979).

\section{Conditional effects of statistical baselines}

Familiarity with social media and general political sophistication may lead individuals to disregard new information about fake news consumption during the 2016 election. With strong existing priors on the issue, heavy social media users and political sophisticates should be less likely to update their views on fake news in the face of new, briefly presented findings (e.g., Hill, 2017). In contrast, those giving the matter less previous thought may be more influenced by baseline information. Similarly, differences in cognitive traits that govern how individuals interact with new information - such as cognitive reflection (Frederick, 2005), need for evidence (Garrett \& Weeks, 2017), and reliance on intuition (Garrett \& Weeks, 2017) - may lead individuals to be more or less open to new statistical information about fake news consumption in forming subjective assessments. Those who are more cognitively reflective, those with a greater need for evidence in forming their beliefs, and those who rely less on intuition may be more likely to consider and be influenced by new evidence.

\section{Effects of different statistical baselines}

Different forms of statistical information such as averages and percentages may be perceived differently (Garcia-Retamero \& Galesic, 2009; Schapira, Davids, McAuliffe, \& Nattinger, 2004; Westwood, Messing, \& Lelkes, 2019). For this reason, we vary our treatments. We test the effects of information about both the percentage of the population exposed to any fake news (about 27\% in the lead-up to the 2016 election) and the average number of fake news articles each 
American read during the time period (5.5 articles). We also test a treatment that includes both baselines. Combining multiple baselines may serve as a further signal-strengthening cue, raising the salience of the fake news problem.

\section{Methods}

\section{Sample}

Our data come from a sample of 981 American adults recruited via Amazon Mechanical Turk in January 2019. Participants were compensated \$.55 for the study, which they completed in an average of 5.92 minutes $(\mathrm{SD}=6.42)$. Our sample had an average age of $36.57(\mathrm{SD}=11.03)$. Just over half of the sample was male (55\%) and approximately three-quarters were white (76\%). The median respondent reported possessing a four-year degree (46\% had less than a four-year degree).

We measure party identification using the standard American National Election Study branching format, where respondents are first asked which party they identify with. Those who say either Republican or Democrat are asked a followup question assessing the strength of their partisanship (either "strong" or "not strong"). Those who do not initially identify with a party are asked a different follow-up question about whether they "lean" toward one party or the other; we code these "leaners" as partisans. (While these measures are often used to construct a seven-point scale ranging from "strong Democrat" to "strong Republican", we create dummy variables for Democrat and Republican identifiers.) Just over half identify as Democrats (56\%) and about a third as Republicans (33\%), with the remainder identifying with neither party. Ideology is nearly identical (51\% selfreport as liberals and 30\% as conservatives). In terms of 2016 presidential candidate support, 29\% report they supported Trump, 46\% say they supported Clinton, and the remainder claim not to have supported either major party candidate.

\section{Design and procedure}

Treatments consisted of information baselines about Americans' exposure to fake news during the 2016 presidential election. Estimates come from Guess and colleagues (2018). Participants were randomly assigned to one of four groups. All groups were informed that we would "ask you about your thoughts about the prevalence of fake news in the lead-up to the 2016 U.S. presidential election (October 7 to November 14, 2016)". The first group $(n=244)$ were then exposed to baseline consumption information in terms of the average number of fake news articles each American saw during the lead-up to the 2016 presidential election, worded as follows: "For your reference, researchers estimate that each voting-age American saw an average of about five and half fake news articles during this time". The second group $(n=251)$ saw baseline consumption information in terms of the percent of Americans exposed to any fake news articles in the leadup to the election, worded as follows: "For your reference, researchers estimate 
that $27 \%$ of voting-age Americans visited a fake news article during this time". A third group $(n=232)$ saw both baseline information treatments. A fourth group $(n=$ 254) served as a control and saw no baseline information.

Participants first provided pre-treatment measures of demographics and moderator variables. Next, they were exposed to the information treatments, before providing outcome measures of their perception of fake news' reach and influence, and their attitudes toward fake news and steps to mitigate it.

\section{Measures}

\section{Dependent variables}

Participants provided a series of estimates about fake news exposure and its influence, as well as attitudes toward fake news.

Perceived overall consumption was measured by asking "How much fake news do you think Americans consumed during the 2016 election?" on a 5-point scale, ranging from "none" (1) to "a great deal" (5), $\mathrm{M}=3.45, \mathrm{SD}=.96$. Perceived consumption trend (2016-present) was measured on a 3-point scale (1 = decreased, $2=$ stayed the same, $3=$ increased), $\mathrm{M}=2.49, \mathrm{SD}=.64$.

Perceived group consumption was gauged for a number of salient demographic groups (see Grinberg et al., 2019; Guess et al., 2018; Guess et al., 2019). Participants were asked to "Use your best estimate. How much fake news did individuals in the following groups" consume during the time period in question. Responses were recorded on a 5-point scale ranging from "much less than average" to "much more than average". Target groups included Trump supporters $(\mathrm{M}=3.88, \mathrm{SD}=1.03)$, Clinton supporters $(\mathrm{M}=3.24, \mathrm{SD}=1.02)$, ages 18-34 $(\mathrm{M}=3.44 \mathrm{SD}=1.04)$, ages $34-59(\mathrm{M}=3.52, \mathrm{SD}=.91)$, ages $60+(\mathrm{M}=3.62$, $\mathrm{SD}=1.17)$, college graduates $(\mathrm{M}=3.02, \mathrm{SD}=1.06)$, and non-college graduates $(\mathrm{M}=3.68, \mathrm{SD}=.97)$.

Participants also provided "downstream" outcomes that may be influenced by shifting perception of the prevalence of fake news using 7-point Likert scales. These included concern about the effects of fake news $(M=5.54, \mathrm{SD}=1.47)$, belief that "fake news is why Donald Trump won the 2016 presidential election" $(\mathrm{M}=4.17, \mathrm{SD}=2.07)$, belief that "Facebook has taken significant action to limit fake news on its platform" $(\mathrm{M}=3.56, \mathrm{SD}=1.71)$, "support [for] increased regulation of fake news by the U.S. government" $(\mathrm{M}=4.81, \mathrm{SD}=1.84)$, and "support [for] public spending on digital media literacy initiatives" $(\mathrm{M}=4.90, \mathrm{SD}=1.68)$. These items formed a scale with only middling reliability (alpha $=.63$ ). Therefore, we examine each outcome individually.

\section{Moderators}

The following measures were considered as potential moderators of baseline consumption information treatment effects. 
Facebook use $(\mathrm{M}=6.02, \mathrm{SD}=2.57)$ was measured on a 9-point scale ranging from "never" to "almost constantly". Political knowledge $(M=2.80, \mathrm{SD}=1.14)$ was an additive index of correct responses to five questions: how many years a US senator is elected for, how many years a US House representative is elected for, how many senators come from each state, how many times an individual can be elected president, and the current UK prime minister. Political interest $(\mathrm{M}=3.35, \mathrm{SD}=1.08)$ was measured on a 5 -point scale ranging from "not at all interested" to "extremely interested".

Cognitive reflection was an additive index of correct responses to three items, using alternate question wording (Patel, 2017) to reduce prior exposure effects $(\mathrm{M}=$ $1.61, \mathrm{SD}=1.20)$. Need for evidence $(\mathrm{M}=5.77, \mathrm{SD}=1.06)$ was the average of three items on a 7-point Likert scale, and reliance on intuition $(\mathrm{M}=4.11, \mathrm{SD}=1.45)$ was the average of four items on a 7-point Likert scale (Garrett \& Weeks, 2017).

\section{Results}

\section{Effects on perceived consumption and concern}

We initially modeled treatment effects on perceived overall consumption, perceived consumption trend (2016-present), and each of the concern/perceived influence outcome measures individually, using OLS regression with each treatment entered as an indicator variable and the control group serving as the reference category. These results are shown in Table 2.1.

This analysis shows no effect of the information baselines on perceived overall consumption (Column 1). However, simultaneous exposure to both information baselines (Treatment 3) increased perception that fake news consumption has increased since 2016 (Column 2), b =.14, $\mathrm{p}=.017$. Similarly, simultaneous exposure to both baselines increased concern about fake news (Column 3), $\mathrm{b}=.26, \mathrm{p}=.049$.

Our results show no baseline information effects on belief that fake news spurred Trump to victory, belief that Facebook has taken significant steps to address fake news, or support for government regulation of fake news (Columns 4-6). We find that exposure to the percent of Americans exposed to fake news in 2016 decreases support for publicly funded media literacy programs (Column 7), $\mathrm{b}=-.34, \mathrm{p}=.024$.

In examination of potential moderators of these treatment effects, we find that the effect of simultaneous exposure to both baselines on increasing concern about fake news was significantly stronger among Trump supporters, $b=.83, p=.006$. The other political and cognitive measures did not moderate the treatment effects.

\section{Effects on group-centric bias}

Next, we examined perceptions of consumption among different demographic groups. First, we present the means of each group's perceived consumption 
18 Benjamin A. Lyons et al.

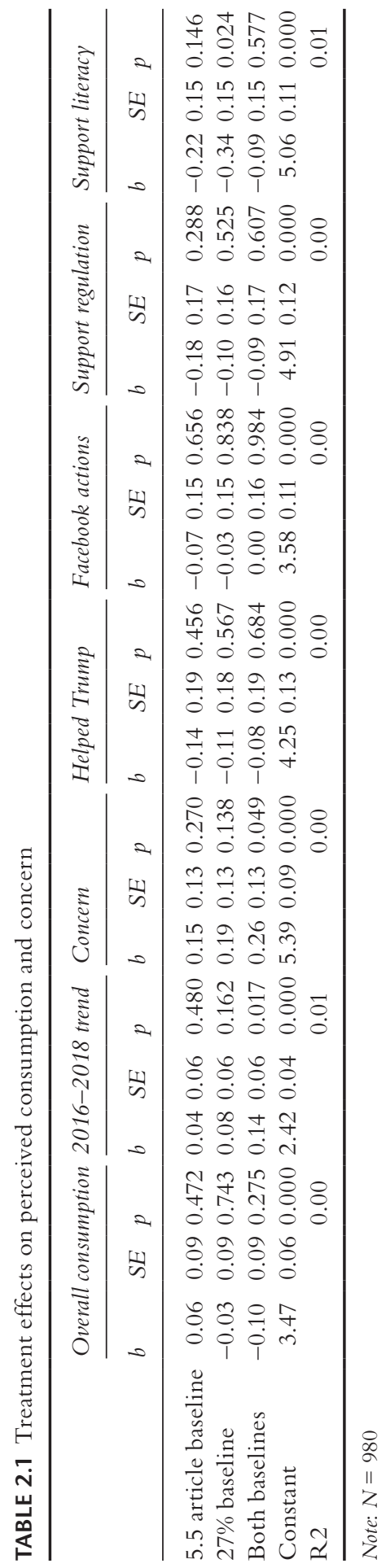



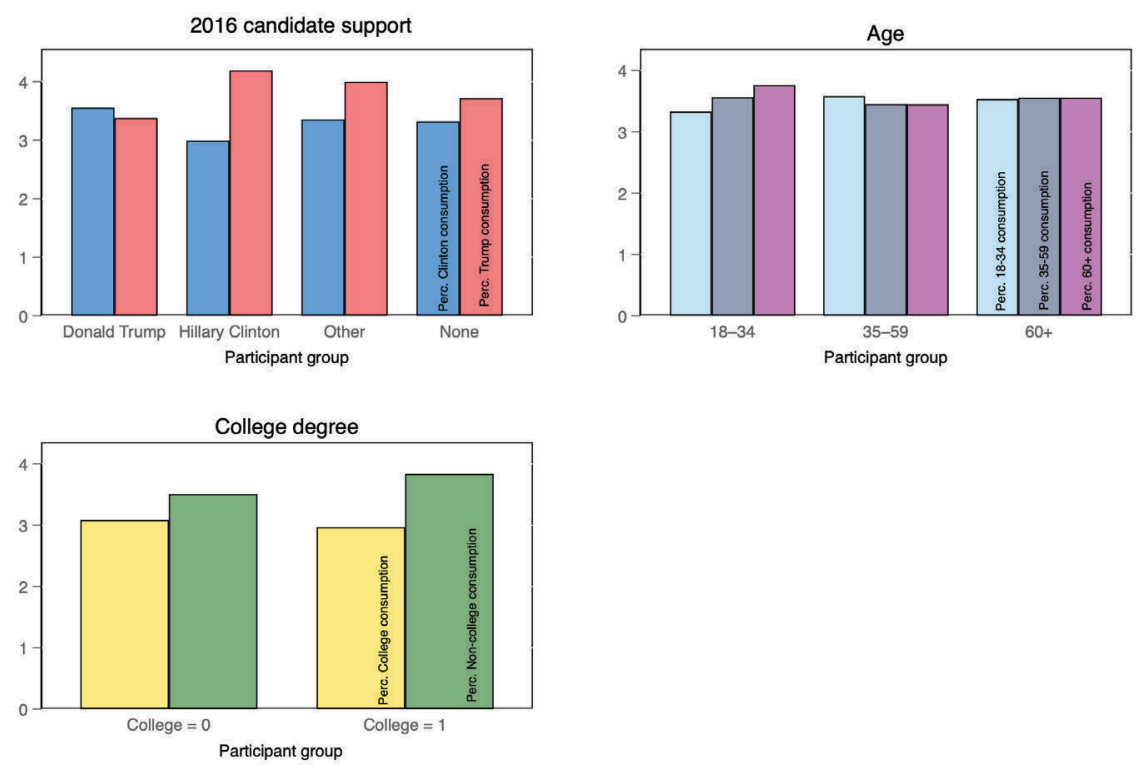

FIGURE 2.1 Perceived consumption of fake news among demographic groups, across participant demographic group

among the in-group and out-groups in Figure 2.1. As shown in this figure, Clinton supporters estimated significantly more fake news consumption among Trump supporters than among their in-group. Trump supporters, meanwhile, estimated that Clinton supporters consumed slightly more fake news than their in-group. College graduates likewise estimated significantly more fake news consumption among non-college graduates than among their in-group. Noncollege graduates, however, also estimated more fake news consumption among non-college graduates, though to a lesser degree. Finally, participants 18-34 years old estimated more fake news consumption among Americans age 60+ than among their in-group, but participants age $60+$ did not exhibit the reverse perception (note that our sample age skewed young: $18-34, n=513 ; 35-59, n=$ $422 ; 60+, n=45)$.

We then computed the difference score for these group perceptions (i.e., perceived Trump supporters' consumption - perceived Clinton supports' consumption), shown across participants' own demographic groups in Figure 2.2.

Next, we modeled perceived consumption of demographic groups using OLS regression. We included our informational baseline treatments and groupmembership categories as predictors. Results are shown in Table 2.2. In each case, relevant group memberships predicted perceived consumption. Trump support (versus those who did not support a candidate) predicted lower perception of Trump supporter fake news consumption $(b=-.49, p<.001)$ and higher perception of Clinton support consumption $(\mathrm{b}=.21, \mathrm{p}=.013)$. Clinton support (versus those who did not support a candidate) predicted lower perception 

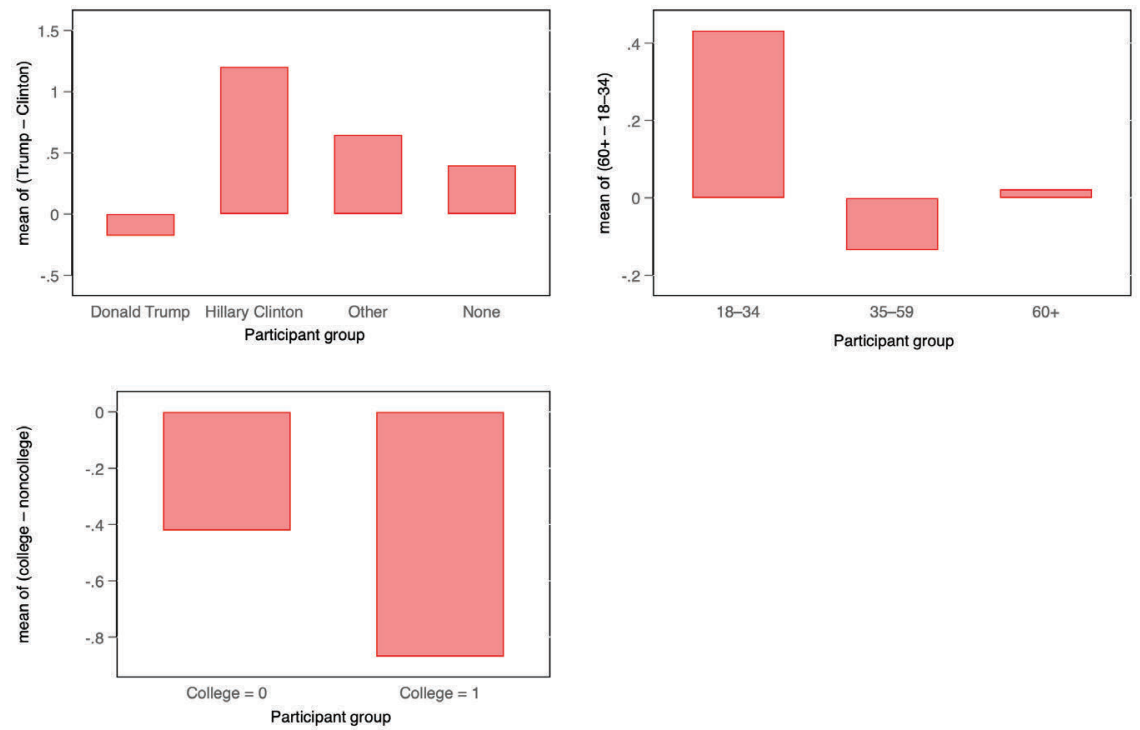

FIGURE 2.2 Mean difference in perceived consumption of fake news, across participant demographic group

of Clinton support consumption $(\mathrm{b}=-.35, \mathrm{p}<.001)$ and higher perception of Trump supporter consumption $(b=.32, p<.001)$. Belonging to the $18-34$ age group (compared to the 35-59 age group) predicted greater perceived fake news consumption among ages $60+(b=.31, p<.001)$ and less perceived consumption among the $18-34$ age group $(b=-.24, p<.001)$. A college degree (versus having a high school degree or less) predicted greater perceived consumption among those without a college degree $(b=.33, \mathrm{p}<.001)$, and less perceived consumption among those with a degree $(b=-.13, p=.064)$.

When adding the full set of group memberships, we see that non-relevant group memberships - specifically, vote support - also predicted perceived consumption of the other target groups. Trump support predicted more perceived consumption among the $18-34$ age group $(\mathrm{b}=.44, \mathrm{p}<.001)$, and less perceived consumption among the $60+$ age group $(b=-.34, p<.001)$ after accounting for age, while Clinton support predicted the reverse - more consumption among both the $60+(\mathrm{b}=.34, \mathrm{p}<.001)$ and $35-59$ age groups $(\mathrm{b}=.23, \mathrm{p}=.002)$. Trump support likewise predicted more perceived consumption among those with a college degree $(b=.54, p<.001)$, whereas Clinton support predicted more perceived consumption among those without a degree $(b=.24, p=.002)$ and less consumption among those with a degree $(b=-.19$, $\mathrm{p}=.019)$, after accounting for educational attainment. In this way, perceived consumption of differing demographic groups may reflect differing conceptions of what "fake news" is among Clinton and Trump supporters. 
TABLE 2.2 Perceived consumption of demographic groups, by treatment and participant demographics

\begin{tabular}{|c|c|c|c|c|c|c|c|c|c|}
\hline & \multicolumn{9}{|l|}{ Age } \\
\hline & \multicolumn{3}{|l|}{$60+$} & \multicolumn{3}{|l|}{$35-59$} & \multicolumn{3}{|l|}{$18-34$} \\
\hline & $b$ & $S E$ & $p$ & $b$ & $S E$ & $p$ & $b$ & $S E$ & $p$ \\
\hline 5.5 article baseline & -0.11 & 0.10 & 0.31 & 0.04 & 0.08 & 0.61 & 0.12 & 0.09 & 0.21 \\
\hline $27 \%$ baseline & -0.11 & 0.10 & 0.28 & -0.05 & 0.08 & 0.57 & -0.03 & 0.09 & 0.73 \\
\hline Both baselines & -0.14 & 0.11 & 0.18 & 0.05 & 0.08 & 0.56 & 0.08 & 0.09 & 0.39 \\
\hline $18-34$ & 0.31 & 0.08 & 0.00 & 0.11 & 0.06 & 0.07 & -0.24 & 0.07 & 0.00 \\
\hline $60+$ & 0.11 & 0.18 & 0.54 & 0.11 & 0.14 & 0.45 & -0.03 & 0.16 & 0.83 \\
\hline Constant & 3.54 & 0.08 & 0.00 & 3.44 & 0.07 & 0.00 & 3.53 & 0.08 & 0.00 \\
\hline $\mathrm{N}$ & & & 980 & & & 980 & & & 979 \\
\hline $\mathrm{R} 2$ & & & 0.02 & & & 0.01 & & & 0.03 \\
\hline
\end{tabular}

Candidate support

\begin{tabular}{|c|c|c|c|c|c|c|}
\hline & \multicolumn{6}{|c|}{ Candidate support } \\
\hline & \multicolumn{3}{|l|}{ Clinton } & \multicolumn{3}{|l|}{ Trump } \\
\hline & $b$ & $S E$ & $p$ & $b$ & $S E$ & $p$ \\
\hline 5.5 article baseline & 0.01 & 0.09 & 0.91 & -0.04 & 0.09 & 0.61 \\
\hline $27 \%$ baseline & -0.14 & 0.09 & 0.11 & 0.06 & 0.09 & 0.47 \\
\hline Both baselines & -0.05 & 0.09 & 0.62 & -0.01 & 0.09 & 0.89 \\
\hline Trump support & 0.21 & 0.09 & 0.01 & -0.49 & 0.08 & 0.00 \\
\hline Clinton support & -0.35 & 0.08 & 0.00 & 0.32 & 0.08 & 0.00 \\
\hline Constant & 3.39 & 0.08 & 0.00 & 3.87 & 0.08 & 0.00 \\
\hline $\mathrm{N}$ & & & 980 & & & 979 \\
\hline R2 & & & 0.06 & & & 0.11 \\
\hline
\end{tabular}

\begin{tabular}{|c|c|c|c|c|c|c|}
\hline & \multicolumn{6}{|c|}{ Education } \\
\hline & \multicolumn{3}{|l|}{ College } & \multicolumn{3}{|c|}{ No college } \\
\hline & $b$ & $S E$ & $p$ & $b$ & $S E$ & $p$ \\
\hline 5.5 article baseline & 0.20 & 0.09 & 0.04 & -0.18 & 0.09 & 0.04 \\
\hline $27 \%$ baseline & -0.22 & 0.09 & 0.02 & -0.16 & 0.09 & 0.06 \\
\hline Both baselines & 0.04 & 0.10 & 0.64 & -0.07 & 0.09 & 0.44 \\
\hline College & -0.13 & 0.07 & 0.06 & 0.33 & 0.06 & 0.00 \\
\hline Constant & 3.09 & 0.08 & 0.00 & 3.61 & 0.07 & 0.00 \\
\hline $\mathrm{N}$ & & & 980 & & & 980 \\
\hline R2 & & & 0.02 & & & 0.03 \\
\hline
\end{tabular}


TABLE 2.3 Perceived consumption difference scores, by treatment and participant demographics

\begin{tabular}{|c|c|c|c|c|c|c|c|c|c|}
\hline & \multicolumn{3}{|c|}{ Trump-Clinton } & \multicolumn{3}{|c|}{ Old-young } & \multicolumn{3}{|c|}{ Non-college-college } \\
\hline & $b$ & $S E$ & $p$ & $b$ & $S E$ & $p$ & $b$ & $S E$ & $p$ \\
\hline 5.5 article baseline & -0.06 & 0.13 & 0.664 & -0.22 & 0.15 & 0.150 & -0.37 & 0.12 & 0.003 \\
\hline $27 \%$ baseline & 0.20 & 0.13 & 0.132 & -0.09 & 0.15 & 0.574 & 0.06 & 0.12 & 0.624 \\
\hline Both baselines & 0.03 & 0.14 & 0.829 & -0.22 & 0.16 & 0.157 & -0.11 & 0.13 & 0.378 \\
\hline Trump support & -0.71 & 0.13 & 0.000 & & & & & & \\
\hline Clinton support & 0.68 & 0.12 & 0.000 & & & & & & \\
\hline $18-34$ & & & & 0.56 & 0.11 & 0.000 & & & \\
\hline $60+$ & & & & 0.15 & 0.27 & 0.575 & & & \\
\hline College & & & & & & & 0.45 & 0.09 & 0.000 \\
\hline Constant & 0.49 & 0.13 & 0.000 & 0.01 & 0.12 & 0.968 & 0.52 & 0.10 & 0.000 \\
\hline $\mathrm{N}$ & & & 979 & & & 979 & & & 980 \\
\hline $\mathrm{R} 2$ & & & 0.14 & & & 0.03 & & & 0.04 \\
\hline
\end{tabular}

We then modeled difference scores using the same procedure. Results are shown in Table 2.3. Group membership also predicted these difference scores: Clinton support $(b=.68, \mathrm{p}<.001)$ and Trump support $(\mathrm{b}=-.71, \mathrm{p}<.001)$ each predicted the Trump-Clinton difference score; age 18-34 $(\mathrm{b}=.56, \mathrm{p}<.001)$ predicted the old-young difference score; and college degree $(b=.45, p<.001)$ predicted the education difference score. In terms of the treatments, only one informational baseline predicted one difference score: exposure to the average number of fake news articles consumed by Americans in 2016 decreased the perceived gap between Americans with and without college degrees in fake news consumption, $\mathrm{b}=-.37, \mathrm{p}=.003$.

Next, we included the interaction terms for each information treatment and group membership category. These results suggest that informational treatments increased the Trump-Clinton difference score for Clinton supporters, as shown in Figure 2.3. Among participants who supported Clinton in 2016, the treatment including information about the percentage of Americans exposed to fake news $(b=.93, p=.004)$ and the treatment including both baselines $(b=.77, p=.024)$ increased the gap between perceived Clinton supporter fake news consumption and perceived Trump supporter fake news consumption.

\section{Discussion}

Public alarm over fake news may be disproportionate to the actual prevalence of exposure and consumption of this fabricated content. How might the provision of actual consumption statistics affect subjective assessments of fake news consumption and concern about its influence? Do such information treatments serve as descriptive norms and lead to a "correction", decreasing subjective 


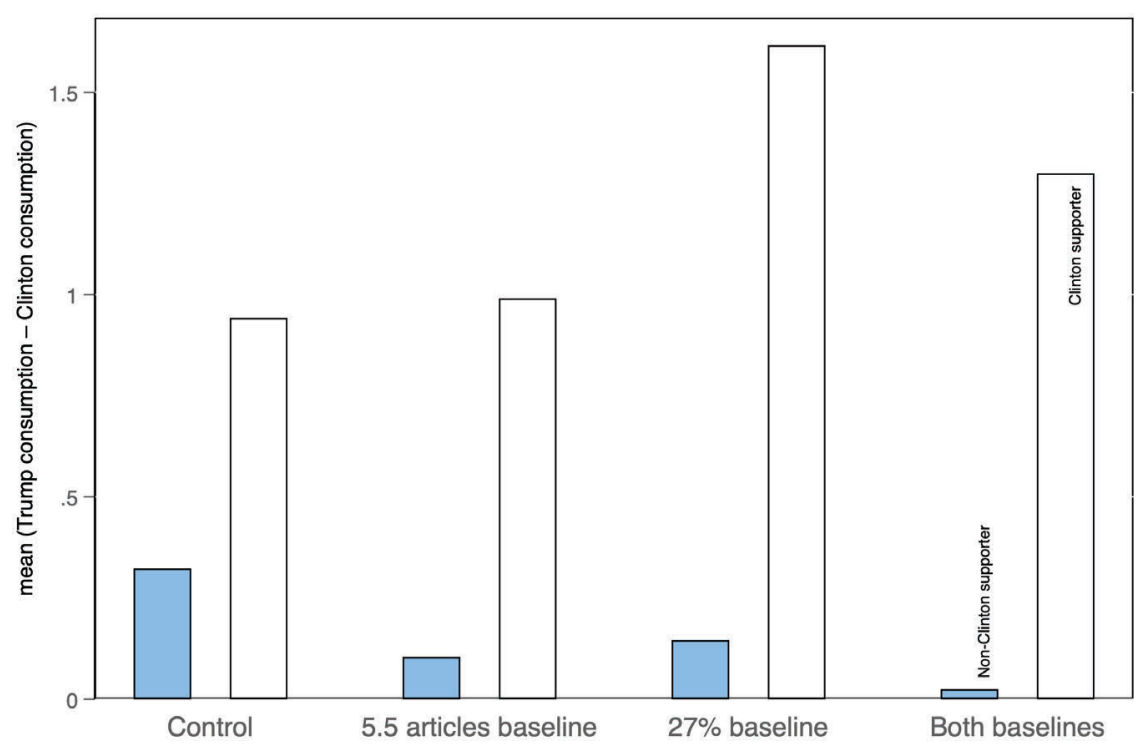

FIGURE 2.3 Mean difference in perceived consumption of fake news, across treatments and participant candidate support

assessments? Or do they serve to increase the salience of the fake news problem and inflate these assessments? We find that the effects of baseline information on fake news perceptions, at least in the format in which we deliver it, are likely small. Moreover, without the proper contextualization, this information may do more to exacerbate than to downplay perceived prevalence, perceived influence, and concern about fake news. Simultaneous exposure to both information baselines (the percent of all Americans exposed to fake news and the average number of articles consumed) increased perception that fake news consumption has increased since 2016, and increased general concern about fake news. We find little evidence that measures of political or cognitive sophistication moderate our treatment effects.

We find sizeable gaps in who the public thinks consumed the most fake news. Not surprisingly, the gaps are driven by the public's own membership in various social categories. Our data show notable in-group biases in perceived consumption across 2016 vote preference, age, and educational attainment subgroups (though these perceptual gaps are not always fully symmetric).

Moreover, non-relevant group memberships - specifically, vote support also predicted perceived consumption of other target groups. Trump supporters assumed the young and the educated were consuming more fake news, even after accounting for their age and education, whereas Clinton supporters assumed the old and those without a college degree were consuming more fake news. These spillover relationships may reflect that the public has a good handle on the differing demographic bases of electoral support of Clinton and Trump, or it may 
reflect differing conceptions of what constitutes "fake news" (or both). Clinton supporters may use a definition closer to academics' definitions of fake news (e.g., Guess et al., 2018), whereas Trump supporters, following his rhetorical cues, may see news outlets such as The New York Times and The Washington Post as "fake news". In some cases (i.e., among Clinton supporters), information about the rate of fake news consumption may widen the perceived gap in consumption between Trump and Clinton supporters.

It is important to note several limitations of this research. First, as the sample of participants was drawn from Amazon Mechanical Turk, which skews young, educated, and liberal, we are limited in making broader generalizations about our findings (but see, e.g., Coppock, 2019; Coppock, Leeper, \& Mullinix, 2018; Mullinix, Leeper, Druckman, \& Freese, 2015). This should be kept in mind particularly when considering the group-differences results that reflect observed (untreated) group difference. Future work should replicate these tests among a nationally representative sample of voters. Next, our manipulations were quite subtle. We did not include a manipulation check in order to simulate the effects of such statistical baselines in limited-attention media browsing environments (e.g., Twitter). This may have resulted in weaker effects on our outcomes of interest. Also in regard to our treatments, it is important to note that not all baselines are created equal (Westwood et al., 2019). There are likely limits to the sort of salience-inducing effect we speculate occurred by way of our treatments. For example, a baseline that stated some event occurred among $5 \%$ of the population may be less likely to drive up concern than a $27 \%$ baseline, so it may be that the availability heuristic is not the only mechanism of baseline effects, instead depending on context. Future studies should manipulate baseline rates to determine whether anchoring plays a role in these effects, and test mechanisms more formally.

Regardless, our findings shed additional light on how the public thinks about and perceives fake news. Empirical estimates derived from social scientific research are unlikely to dramatically reshape public perceptions of fake news as a social issue all on their own. The public's social identities likely shape who they see as the prototypical fake news consumer, and in that sense, what they define as fake news itself. Toward that end, media literacy initiatives may focus on communicating the basics of what constitutes legitimate journalism.

Fake news is seen by many as a real and present danger to democracy. The European Union organized a high-level group to study the problem, and several national governments have held hearings or formed committees to examine the problem. At the same time, the accumulating academic evidence is that fake news consumption is fairly limited, and there is little evidence to suggest it is changing election outcomes. The results in this chapter suggest that it may be hard to sway beliefs about fake news consumption. This finding may be a problem.

As misinformation researchers, we are acutely aware of the corrosive effects that misinformation can have on politics and society. Nonetheless, the deleterious effects of fake news, specifically, must be appropriately calibrated. While 
misinformation is indeed a serious problem facing society, it is important not to be distracted by these potentially more niche forms while letting misinformation spread unabated by other means. For example, misinformation communicated by elites - especially when they have direct access to much larger audiences via social media - is likely a more severe problem than fake news websites. It would be a shame if efforts to constrain misinformation solved the problem of fake news, but in so doing gave a free pass to other forms of deception and dissembling.

\section{References}

Ahler, D. J., \& Sood, G. (2018). The parties in our heads: Misperceptions about party composition and their consequences. The Journal of Politics, 80(3), 964-981.

An, S. (2008). Antidepressant direct-to-consumer advertising and social perception of the prevalence of depression: Application of the availability heuristic. Health Communication, 23(6), 499-505.

Barthel, M., Mitchell, A., \& Holcomb, J. (2016). Many Americans believe fake news is sowing confusion. Pew Research. Retrieved from www.journalism.org/2016/12/15/ many-americans-believe-fake-news-is-sowing-confusion/

Carey, B. (2018, January 2). "Fake news": Wide reach but little impact, study suggests. The New York Times. Retrieved from www.nytimes.com/2018/01/02/health/fakenews-conservative-liberal.html

Carroll, J. S. (1978). The effect of imagining an event on expectations for the event: An interpretation in terms of the availability heuristic. Journal of Experimental Social Psychology, 14(1), 88-96.

Coppock, A. (2019). Generalizing from survey experiments conducted on Mechanical Turk: A replication approach. Political Science Research and Methods, 7(3), 613-628.

Coppock, A., Leeper, T. J., \& Mullinix, K. J. (2018). Generalizability of heterogeneous treatment effect estimates across samples. Proceedings of the National Academy of Sciences, 115(49), 12441-12446.

Ecker, U. K., Lewandowsky, S., Chang, E. P., \& Pillai, R. (2014). The effects of subtle misinformation in news headlines. Journal of Experimental Psychology: Applied, 20(4), 323.

Folkes, V. S. (1988). The availability heuristic and perceived risk. Journal of Consumer Research, 15(1), 13-23.

Fox, A. (2019, January). Majority of Americans were not exposed to "fake news" in 2016 U.S. election, Twitter study suggests. Retrieved from www.sciencemag.org/ news/2019/01/majority-americans-were-not-exposed-fake-news-2016-us-electiontwitter-study-suggests

Frederick, S. (2005). Cognitive reflection and decision making. Journal of Economic Perspectives, 19(4), 25-42.

Garcia-Retamero, R., \& Galesic, M. (2009). Communicating treatment risk reduction to people with low numeracy skills: A cross-cultural comparison. American Journal of Public Health, 99(12), 2196-2202.

Garrett, R. K., \& Weeks, B. E. (2017). Epistemic beliefs' role in promoting misperceptions and conspiracist ideation. PloS One, 12(9), e0184733.

Grinberg, N., Joseph, K., Friedland, L., Swire-Thompson, B., \& Lazer, D. (2019). Fake news on Twitter during the 2016 US presidential election. Science, 363(6425), 374-378.

Guess, A., Lyons, B. A., Montgomery, J., Nyhan, B., \& Reifler, J. (2019). Fake news, Facebook ads, and misperceptions: Assessing information quality in the 2018 U.S. 
midterm election campaign. Retrieved from www.dartmouth.edu/ nyhan/fakenews-2018.pdf

Guess, A., Nagler, J., \& Tucker, J. (2019). Less than you think: Prevalence and predictors of fake news dissemination on Facebook. Science Advances, 5(1), eaau4586.

Guess, A., Nyhan, B., \& Reifler, J. (2018). Selective exposure to misinformation: Evidence from the consumption of fake news during the 2016 US presidential campaign. Retrieved from www.dartmouth.edu/ nyhan/fake-news-2016.pdf

Hill, S. J. (2017). Learning together slowly: Bayesian learning about political facts. The Journal of Politics, 79(4), 1403-1418.

Hoffrage, U., Lindsey, S., Hertwig, R., \& Gigerenzer, G. (2000). Communicating statistical information. Science, 290, 2261-2262. doi: 10.1126/science.290.5500.2261

Kessler, S., Levine, E. K., Opitz, J. M., \& Reynolds, J. F. (1987). Psychological aspects of genetic counseling: IV. The subjective assessment of probability. American Journal of Medical Genetics, 28(2), 361-370.

MacLeod, C., \& Campbell, L. (1992). Memory accessibility and probability judgments: An experimental evaluation of the availability heuristic. Journal of Personality and Social Psychology, 63(6), 890.

Mullinix, K. J., Leeper, T. J., Druckman, J. N., \& Freese, J. (2015). The generalizability of survey experiments. Journal of Experimental Political Science, 2(2), 109-138.

Neighbors, C., Dillard, A. J., Lewis, M. A., Bergstrom, R. L., \& Neil, T. A. (2006). Normative misperceptions and temporal precedence of perceived norms and drinking. Journal of Studies on Alcohol, 67(2), 290-299.

Neisser, U. (1978). Memory: What are the important questions? In M. M. Gruneberg, P. E. Morris, \& H. N. Sykes (Eds.), Practical aspects of memory (pp. 3-24). London: Academic Press. [Reprinted in Neisser, U. (1982). Memory: What are the important questions. Memory Observed: Remembering in Natural Contexts, 3-19].

Patel, N. (2017). The cognitive reflection test: A measure of intuition/reflection, numeracy, and insight problem solving, and the implications for understanding real-world judgments and beliefs. (Unpublished doctoral dissertation). Columbia, MO: University of Missouri.

Rimal, R. N., \& Real, K. (2005). How behaviors are influenced by perceived norms: A test of the theory of normative social behavior. Communication Research, 32(3), 389-414.

Schapira, M. M., Davids, S. L., McAuliffe, T. L., \& Nattinger, A. B. (2004). Agreement between scales in the measurement of breast cancer risk perceptions. Risk Analysis: An International Journal, 24(3), 665-673.

Turner, J. C., Brown, R. J., \& Tajfel, H. (1979). Social comparison and group interest in ingroup favouritism. European Journal of Social Psychology, 9(2), 187-204.

Tversky, A., \& Kahneman, D. (1974). Judgment under uncertainty: Heuristics and biases. Science, 185(4157), 1124-1131.

Westwood, S., Messing, S., \& Lelkes, Y. (2019). Projecting confidence: How the probabilistic horse race confuses and demobilizes the public. Retrieved from https://papers. ssrn.com/sol3/papers.cfm?abstract_id $=3117054$ 